\title{
Transformation of Terpene Synthase from Polyporus brumalis in Pichia pastoris for Recombinant Enzyme Production ${ }^{1}$
}

\author{
Ji-Eun $\mathrm{An}^{2} \cdot$ Su-Yeon Lee ${ }^{3} \cdot$ Sun-Hwa Ryu ${ }^{4} \cdot$ Myungkil Kim $\mathbb{D}^{5, \dagger}$
}

\begin{abstract}
Terpenoids have a wide range of biological functions and have extensive applications in the pharmaceutical, cosmetic, and flavoring industry. The white-rot fungus, Polyporus brumalis, is able to synthesize terpenoids via terpene synthase, which catalyzes an important step that forms a large variety of sesquiterpene products from farnesyl pyrophosphate (FPP). To improve the production of sesquiterpenes, the terpene synthase gene was isolated from Polyporus brumalis and was heterologously transformed into a Pichia pastoris strain. The open reading frame of the isolated gene (approximately $1.2 \mathrm{~kb}$ ) was inserted into Pichia pastoris to obtain a recombinant enzyme. Five transformants were obtained and the expression of terpene synthase was analyzed at the transcript level by reverse transcription PCR (polymerase chain reaction) and at the protein level by SDS-PAGE (sodium dodecyl sulfate polyacrylamide gel electrophoresis). Expression of the terpene synthase gene product was elevated in the transformants and as expected the molecular weight of the protein was approximately $45 \mathrm{kDa}$. These recombinant enzymes have potential practical applications and future studies should focus on their functional characterization.
\end{abstract}

Keywords: Polyporus brumalis, Pichia pastoris, terpene synthase, transformation

\section{INTRODUCTION}

Terpenoids are secondary plant metabolites with important protective roles and a variety of applications in various fields such as fragrances and flavors, pharmaceutical agents, and also as insecticides (Tholl, 2006; Bicas et al., 2008).

Terpenes are biosynthesized from the C5 universal precursors isopentenyl diphosphate (IPP) and dimethylallyl diphosphate (DMAPP). Prenyltransferases assemble IPP and DMAPP into linear prenyl diphosphate precursors such as farnesyl diphosphate (FPP, C15), which are then rearranged by terpene synthases (TPS) into a variety of distinct terpenes such as sesquiterpenes (C15) (Peralta-Yahya et al., 2011; Schnee et al., 2002). Sesquiterpenes, composed of three isoprene units, exhibit diverse antioxidant, antimicrobial, and antitumor bioactivities (Sandler et al., 2006). Although sesquiterpene compounds are naturally produced in plants, their yields from biological sources is generally low. In addition, the chemical synthesis of natural products is a difficult and expensive procedure (Huang et al., 2008). Owing

${ }^{1}$ Date Received May 24, 2018, Date Accepted July 10, 2018

${ }^{2}$ Division of Wood Chemistry, Department of Forest Products, National Institute of Forest Science, Seoul 02455, Republic of Korea

${ }^{3}$ Forest Biomaterials Research Center, National Institute of Forest Science, Jinju 52817, Republic of Korea

${ }^{4}$ Division of Forest Industry Research, Department of Forest Policy and Economics, National Institute of Forest Science, Seoul 02455, Republic of Korea

${ }^{5}$ Division of Global Forestry, Department of Forest Policy and Economics, National Institute of Forest Science, Seoul 02455, Republic of Korea

† Corresponding author: Myungkil Kim (e-mail: mkkim0201@korea.kr, ORCID: 0000-0002-2130-7517) 
to the availability of metabolic engineering systems and fermentation techniques, microorganisms have been established as beneficial platforms for the mass production of useful substances, and as alternatives to less productive plants. Various recombinant fungal enzymes have so far been produced by engineered microbial platforms and are directly used for the biobleaching of softwood kraft pulp (Kim et al., 2007).

Previously, we found that Polyporus brumalis, white rot fungus, has a unique ability of synthesizing eudesmane-type sesquiterpenoids as secondary metabolites (Lee et al., 2016). Furthermore, TPS, which is highly expressed in the presence of magnesium by $P$. brumalis, identified by a transcriptome analysis and sequencing of the full-length terpene synthase, including a metal-binding motif (DEXXD) (Gao et al., 2012), has been isolated by RACE (rapid amplification of cDNA ends)-PCR. TPS of $P$. brumalis is phylogenetically closely related to TPS of other basidiomycetes. The amino acid similarity between this sequence compared with that of Neolentinus lepideus HHB14362 ss-1 is $69 \%$, Gloeophyllum trabeum ATCC 11539 is $68 \%$, and Fomitiporia mediterranea MF3/22 is 65\% (Lee et al., 2017). TPS is assumed to be necessary for the formation of a cyclic structure by removing a phosphate group from FPP and inducing cyclization in sesquiterpenoids (Lee et al., 2017). Therefore, we tried to transformation the $P$. brumalis terpene synthase gene in Pichia pastoris to produce a recombinant enzyme and functionally characterized this recombinant TPS.

\section{MATERIALS and METHODS}

\subsection{Fungal culture}

P. brumalis was obtained from the Korean Collection for Type Cultures (KCTC46459). Fungi were inoculated onto potato dextrose agar (BD Difco, Franklin Lakes,
$\mathrm{NJ}, \mathrm{USA}$ ) and were incubated in the stationary phase at $28^{\circ} \mathrm{C}$ for 7 days. Subsequently, mycelia were fully grown on Petri dishes and a blade was used to separate the mycelial layer covering the agar medium from the medium. Then, the mycelium were homogenized for $30 \mathrm{~s}$ in $20 \mathrm{ml}$ of distilled water and the homogenized suspension was inoculated into a modified medium including magnesium (Lee et al., 2016). The inoculated fungus was incubated for 7 days at $28^{\circ} \mathrm{C}$ under 120 rpm shaking.

\subsection{Cloning of the terpene synthase gene by RT-PCR}

Total RNA was extracted with Hybrid-R (GeneAll, Seoul, Korea) from the incubated $P$. brumalis mycelium (described above). The 2100 Bioanalyzer (Agilent, Santa Clara, CA, USA) was used to determine the amount and quality of RNA. cDNAs were synthesized by transcribing $1 \mu \mathrm{g}$ of RNA with MMLV reverse transcriptase (Promega, Madison, WI, USA), as recommended by the manufacturer. Fragments, approximately $1.2 \mathrm{~kb}$ in size, were amplified with pairs of TPS ORF primers (Forward: $5^{\prime}$-TGTACTATGCT CACTTCCACCA-3' and Reverse: 5' -CTCATCCC ACGGTTACAGG-3' ). PCR was performed as follows: initial denaturation at $94^{\circ} \mathrm{C}$ for $3 \mathrm{~min}, 30$ cycles of denaturation at $94^{\circ} \mathrm{C}$ for $1 \mathrm{~min}$, annealing at $55^{\circ} \mathrm{C}$ for $1 \mathrm{~min}$, extension at $72^{\circ} \mathrm{C}$ for $3 \mathrm{~min}$, and a final 5-min extension at $72^{\circ} \mathrm{C}$. The amplified fragments were sub-cloned into a pCR2.1-TOPO (Invitrogen, Carlsbad, CA, USA) vector and the plasmid DNA was sequenced.

\subsection{Cloning into the $P$. pastoris expression vector}

The terpene synthase open reading frame (ORF) was separated from pCR2.1-TOPO by digesting with EcoRI and NotI restriction enzymes and was inserted into the 
Transformation of Terpene Synthase from Polyporus brumalis in Pichia pastoris for Recombinant Enzyme Production

pPICZ $\alpha$ C vector (Invitrogen) linearized with EcoRI and NotI. The combined cassette was amplified in the Escherichia coli $\mathrm{DH} 5 \alpha$ strain using heat shock (Sambrook and Russell, 2001) and the selection was performed on low-salt LB agar medium (BD Difco) containing $25 \mu \mathrm{g} / \mathrm{ml}$ zeocin.

\subsection{Transformation of $P$. pastoris by electroporation and expression}

P. pastoris X33 was transformed by electric shock (following methods described in the Pichia expression system manual, with slight modifications; Invitrogen). Plasmid DNA was digested with PmeI restriction enzyme and was linearized prior to transformation. For pre-culture, a single $P$. pastoris colony was inoculated in $5 \mathrm{ml}$ of YPD medium (1\% Bacto-Yeast Extract, 2\% Bacto-Peptone, $2 \%$ dextrose) and incubated overnight at $30^{\circ} \mathrm{C}$ under $180 \mathrm{rpm}$ shaking. The incubated culture was re-inoculated in fresh YPD medium (180 rpm, $30^{\circ} \mathrm{C}$ ) and was allowed to grow until an $\mathrm{OD}_{600}$ of 1.3-1.5 was reached. Then, the cells were harvested by centrifugation at $4000 \mathrm{rpm}$ for $5 \mathrm{~min}$ at $4^{\circ} \mathrm{C}$ and the pellet was washed twice with $20 \mathrm{ml}$ of ice-cold sterile water. A final round of washing was performed with ice-cold $1 \mathrm{M}$ sorbitol and the cell pellet was resuspended in $0.4 \mathrm{ml}$ of ice-cold $1 \mathrm{M}$ sorbitol. An aliquot of yeast cells $(80 \mu \mathrm{l})$ was mixed with $0.1 \mu \mathrm{g}$ of linearized plasmid DNA. This mixture was transferred to a chilled electroporation cuvette ( $0.2 \mathrm{~cm}$ gap) and was subjected to a pulsed at $2 \mathrm{kV}, 25 \mu \mathrm{F}, 200 \Omega$ (Bio-Rad Gene Pulser; Hercules, CA, USA). The cell suspension with $1 \mathrm{M}$ sorbitol was transferred to a $50 \mathrm{ml}$ centrifuge tube and was incubated at $30^{\circ} \mathrm{C}$ under $180 \mathrm{rpm}$ shaking. After incubation for $1 \mathrm{~h}$, the cells were spread on YPD plates supplemented with zeocin $(100 \mu \mathrm{g} / \mathrm{ml})$ and were incubated at $30^{\circ} \mathrm{C}$ until colonies appeared. All the transformants were confirmed by colony PCR and sequencing.

\subsection{Expression of the desired gene in transformants}

\subsubsection{Growth of strains}

Single transformant colonies were selected from agar plates and were transferred to $5 \mathrm{ml}$ of BMGY medium (1.34\% yeast nitrogen base with ammonium sulfate without amino acids, $1 \%$ yeast extract, $2 \%$ peptone, $100 \mathrm{mM}$ potassium phosphate (pH 6), $0.4 \mu \mathrm{g} / \mathrm{ml}$ biotin, $10 \%$ glycerol) in a $50 \mathrm{ml}$ Falcon tubes and incubated at $30^{\circ} \mathrm{C}$ and $200 \mathrm{rpm}$ for $18 \mathrm{~h}$. Subsequently, $0.5 \mathrm{ml}$ of this seed culture was inoculated into $50 \mathrm{ml}$ of BMGY medium in a $250 \mathrm{ml}$ flask and was grown until an $\mathrm{OD}_{600}$ of 4-6 was reached. The cultured cells were harvested by centrifugation at $4000 \mathrm{rpm}$ for $5 \mathrm{~min}$ at $4^{\circ} \mathrm{C}$ and the pellet was washed with sterile water.

The pellet was resuspended in $50 \mathrm{ml}$ of BMMY medium (1.34\% yeast nitrogen base with ammonium sulfate without amino acids, $1 \%$ yeast extract, $2 \%$ peptone, $100 \mathrm{mM}$ potassium phosphate (pH 6), $0.4 \mu \mathrm{g} / \mathrm{ml}$ biotin, $0.5 \%$ methanol) and incubated for $72 \mathrm{~h}$ at $30^{\circ} \mathrm{C}$ and $200 \mathrm{rpm}$. Furthermore, to maintain a final concentration of $0.5 \%$ necessary for inducing the terpene synthase expression, methanol (100\%) was added to $50 \mathrm{ml}$ of BMMY medium every day.

\subsubsection{Determination of mRNA expression}

AccuPower RT/PCR Premix (Bioneer, Daejeon, Korea) was used to detect the mRNA encoding terpene synthase; 18S rRNA served as the internal control. The reaction mixture $(20 \mu \mathrm{l})$ was analyzed by gel electrophoresis. Gene-specific PCR primers were designed from tail region of the TPS gene. TPS partial primer set 1 (F: 5' -ACCATTCGCACCATCGACAGC TACC-3' , R: 5' -GCTCATCCCACGGTTACAGGGCTC$3^{\prime}$ ) generated a 630 bp product and TPS partial primer set 2 (F: 5' -GAACTCCGTGATTGTCCAGGC-3' , R: 5' -TACACCGCGACCTGCTTGT-3' ) amplified 
TPS partial primer set 1

TPS partial primer set $2 \leftarrow$

\section{TPS ORF(1.2 kb)}

Fig. 1. Position of the partial primer for RT-PCR.

a 414 bp product (Fig. 1). The expression level of $18 \mathrm{~S}$ rRNA was determined by RT-PCR using commercial primers (QuantumRNA Universal 18S; Ambion, Foster City, CA, USA) to validate the concentration of cDNA.

\subsubsection{Protein estimation using SDS-PAGE}

The incubated cells (2.5.1) were harvested by centrifugation at 13,000 rpm for $1 \mathrm{~min}$ and resuspended in lysis buffer (100 mM Tris-HCl, pH 7.4, $150 \mathrm{mM}$ $\mathrm{NaCl}, \quad 0.5 \%$ Triton X-100, $1 \times$ protease inhibitor (leupeptin hemisulfate salt; Sigma, St. Louis, MO, USA)). The resuspended cells were disrupted by bead beating and debris were removed by centrifugation at $13,000 \mathrm{rpm}$ for $15 \mathrm{~min}$ at $4^{\circ} \mathrm{C}$. The proteins in the supernatant were resolved by $12 \%$ SDS-PAGE (Kim et al., 2013).

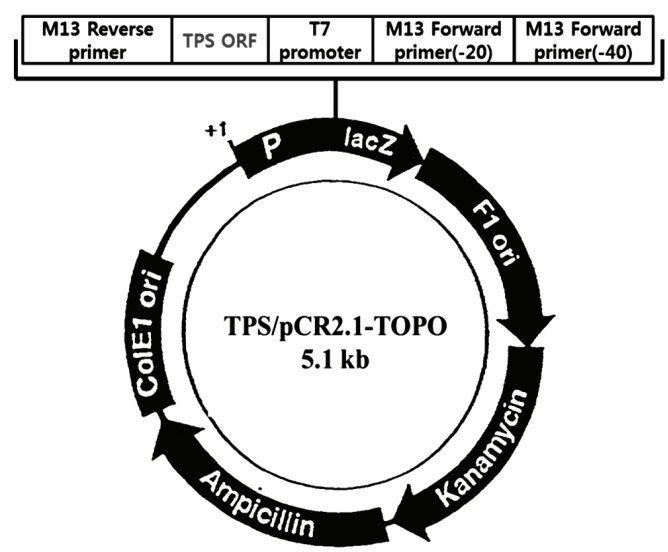

(a)

\section{RESULTS and DISCUSSION}

\subsection{Construction of the cassette for TPS expression}

Terpene synthase genes have a metal-binding region (DEXXD, NSE) that is highly conserved among different taxa. In a previous study, we used RACE-PCR to identify the sequence of an unknown region flanked by conserved sequences and thereby obtained ORF sequences of approximately $1.2 \mathrm{~kb}$ size. For ease of insertion into the yeast expression vector, the terpene synthase gene ORF obtained by RT-PCR was subcloned into a pCR2.1-Topo vector and a TPS/pCR2.1TOPO of approximately $5.1 \mathrm{~kb}$ was obtained (Fig. 2A). Following this, the TPS ORF of the pCR2.1-Topo clone was separated and was transferred to a Pichia expression vector, $\mathrm{pPICZ} \alpha \mathrm{C}$, in-frame with the $\alpha$-factor signal sequence for secretion. This resulted in a $4.8 \mathrm{~kb}$ expression cassette, TPS/pPICZ $\alpha$ C (Fig. 2B). The cassette for expression was analyzed by digestion and sequencing. These results indicated that all the cloning steps were performed correctly. EcoR1 and Not1

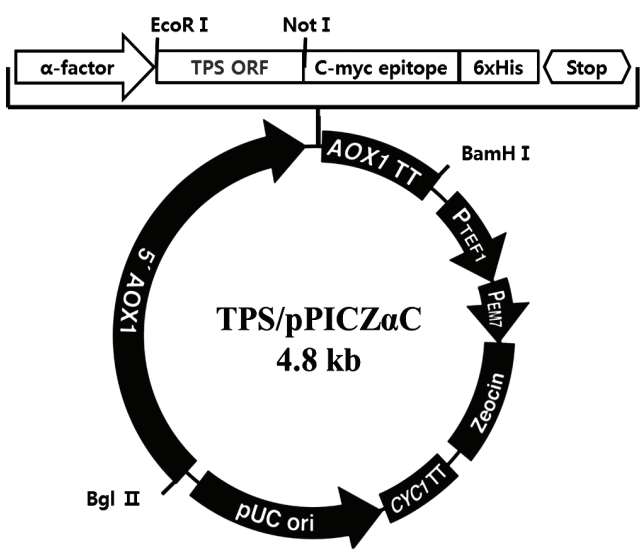

(b)

Fig. 2. (A) TPS/pCR2.1-TOPO vector for subcloning into the Pichia expression vector, (B) TPS/pPICZ $\alpha$ C cassette for terpene synthase expression in Pichia pastoris. 


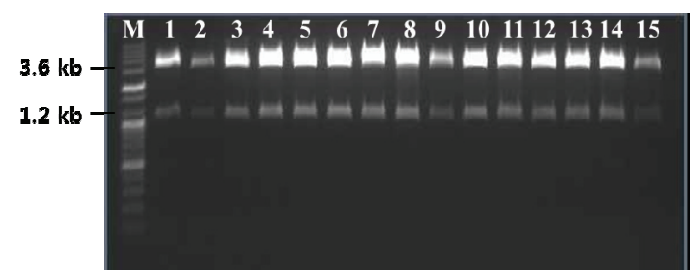

Fig. 3. Analysis of TPS/pPICZ $\alpha \mathrm{C}$ using EcoRI and NotI. Lane M: 100 bp Plus DNA Ladder (Bioneer). Lanes 1-15: Digestion products of TPS $/ \mathrm{pPICZ} \alpha$ clones $(1.2 \mathrm{~kb})$.

restriction enzymes were used to confirm the cloning. The structure contained a TPS ORF of approximately $1.2 \mathrm{~kb}$ (Fig. 3).

\subsection{Transformation}

As a basis for functional and structural studies, the TPS cDNA was heterologously expressed in P. pastoris. The linearized DNA was directly introduced without carrier DNA and the transformed cells, obtained by using an electroporation device, were plated on YPD medium supplemented with zeocin $(100 \mu \mathrm{g} / \mathrm{ml})$. Out of the more than 20 obtained candidates, five healthy appearing candidate single cells were selected. The small number of transformants can be explained by

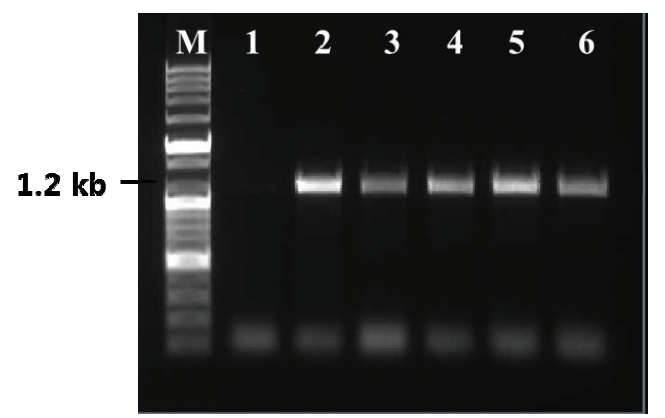

Fig. 4. Colony PCR of transformed Pichia pastoris strains. Lane M: 100 bp Plus DNA Ladder (Bioneer). Lane 1: Wild-type Pichia pastoris. Lanes 2-6: TPS transformants. the scale of the culture, the amount of plasmid used, transformation without carrier DNA, and dilution during the plating step. The estimated transformation efficiency was $8 \times 10^{2} / 1 \mu \mathrm{g}$ of linearized DNA. Gene insertion in the resulting transformants was confirmed by colony PCR, which confirmed the size of the TPS ORF to be $1.2 \mathrm{~kb}$ (Fig. 4), and insertion of the gene without any mutations was confirmed by sequencing (not shown).

\subsection{Gene expression analysis}

\subsection{1. mRNA expression}

Yeast cells grown in BMGY medium, until an optical density of 2-6 at $600 \mathrm{~nm}$, were transferred to an induction medium and were cultured for $72 \mathrm{~h}$. RNA was extracted from the cultured yeast cells and was evaluated by RT-PCR using primers, which amplify the partial region of TPS ORF, to confirm expression. For all transformants, PCR products were obtained using TPS primers. However, wild-type yeast used as a negative control showed no amplification by RT-PCR using TPS targeting primers (Fig. 5). Thus, the TPS gene was properly expressed in the transgenic system.

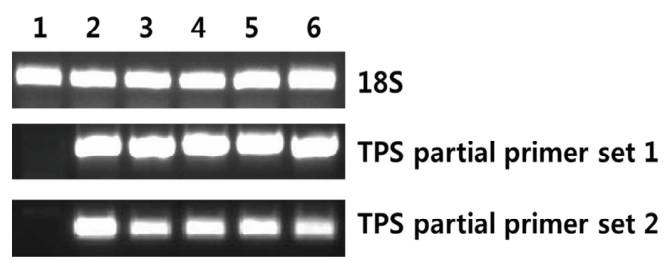

Fig. 5. RT-PCR analysis for the expression of the terpene synthase gene in Pichia pastoris transformants. The expression of 18S rRNA was determined by RT-PCR using commercial primers and the concentration of cDNA was validated. Expression of the partial region of TPS was determined by RT-PCR using TPS partial primer set 1 and set 2. Lane M: 100 bp Plus DNA Ladder (Bioneer). Lane 1: Wild-type Pichia pastoris. Lanes 2-6: TPS transformants. 


\subsubsection{Protein expression}

SDS-PAGE was used to confirm the expression of TPS in the transformants. As Fig. 6 shows, the molecular weight of the secreted TPS was about $45 \mathrm{kDa}$. This was consistent with the predicted molecular weight computed using Compute $\mathrm{pI} / \mathrm{Mw}$ tool. The following factors may have contributed to the faint protein band: gene copy number, site and mode of chromosomal integration of the expression cassette, $5^{\prime}$ and $3^{\prime}$ untranslated regions of mRNA, A+T composition of cDNA, transcription and translation blocks, nature of the secretion signal, endogenous protease activity, host strain physiology, media and growth conditions, and fermentation parameters (Dong et al., 2006).

To evaluate the activity of the recombinant enzyme, we employed a colorimetric assay using malachite green pyrophosphate (MG). In this assay, a monophosphate (Pi) produced by the reaction of the substrate FPP with terpene synthase reacts with malachite green and results in a green color (Vardakou et al., 2014). MG assay was performed using culture media of each strain. Disappointingly, the results for both the wild type and the transformants were unclear (data not shown). Since the MG assay does not directly detect TPS activity,

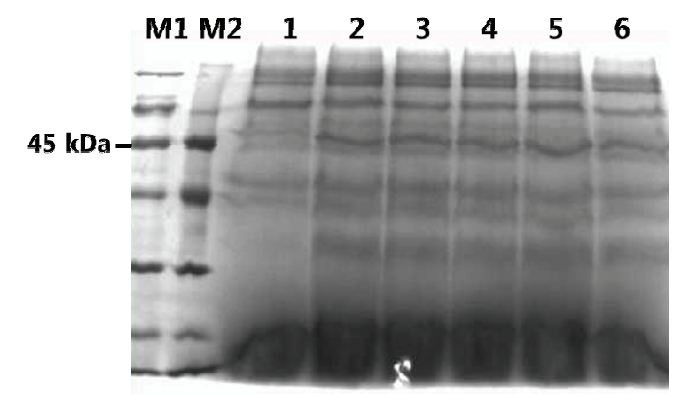

Fig. 6. SDS-PAGE analysis of the recombinant TPS in Pichia pastoris. Lane M1: broad range protein marker (Bioneer). Lane M2: low range protein marker(Bioneer). Lane 1: concentrated supernatant from $P$. pastoris wild-type. Lane 2-6: concentrated supernatant from TPS transformants after $72 \mathrm{~h}$. the components of the medium or other factors may have affected the results of this assay. A method for the direct measurement of TPS activity has not yet been established and should be a focus of future research.

$P$. pastoris was used in this study because it can be grown to high cell densities and genetic manipulation in this species is easier than in fungi. Other benefits of the $P$. pastoris system include the strong $A O X 1$ promoters available to drive the expression of foreign proteins of interest (Cereghino et al., 2000; Ahmad et al., 2014), thus, enabling the production of large quantities of the target protein with relative technical ease and at a lower cost compared with most other eukaryotic systems (Daly et al., 2005; Jönsson et al., 1997). $P$. pastoris is a suitable host for eukaryotic heterologous expression systems and this system has been used to achieve a heterologous expression of the MnP5 gene (Lee et al., 2005). In this study, we obtained stable transgenic strains for the production of recombinant TPS using a heterologous expression. Further studies including the development of a method for measuring the activity of recombinant proteins generated by transformants are needed.

\section{CONCLUSION}

$P$. pastoris can be genetically manipulated to produce various compounds that are only produced naturally in higher eukaryotes. In this study, five TPS expressing transformants were obtained. We could confirm that genes of transgenic strains were expressed at transcription level. However, the activity of the recombinant proteins could not be confirmed. Thus, the establishment of a method for measuring TPS activity is necessary. The recombinant enzymes created in this study would prove useful in developing methods for measuring enzyme activity and in understanding the formation of the cyclic structure from FPP during sesquiterpenoid synthesis. 


\section{ACKNOWLEDGMENT}

This research was supported by the Research Program of the National Institute of Forest Science (NIFoS), Seoul, Korea.

\section{REFERENCES}

Ahmad, M., Hirz, M., Pichler, H., Schwab, H. 2014. Protein expression in Pichia pastoris: recent achievements and perspectives for heterologous protein production. Applied Microbiology and Biotechnology 98(12): 5301-5317.

Beibei, H., Jing, G., Bo, Y., Xiaojing Y., Lianna, S., Wansheng, C., 2008. Heterologous production of secondary metabolites as pharmaceuticals in Saccharomyces cerevisiae. Biotechnology Letters 30(7): 1121-1137.

Bicas, J.L., Fontanille, P., Pastore, G.M., Larroche, C. 2008. Characterization of monoterpene biotransformation in two pseudomonads. Journal of Applied Microbiology 105(6): 1991-2001.

Cereghino, J.L., Cregg, J.M. 2000. Heterologous protein expression in the methylotrophic yeast Pichia pastoris. FEMS Microbiology Reviews 24(1): 45-66.

Daly, R., Hearn, M.T.W. 2005. Expression of heterologous proteins in Pichia pastoris: a useful experimental tool in protein engineering and production. Journal of Molecular Recognition 18(2): 119-138.

Gao, Y., Honzatko, R.B., Peters, R.J. 2012. Terpenoid synthase structures: a so far incomplete view of complex catalysis. Natural Product Reports 29(10): 1153-1175.

Jonsson, L.J., Saloheimo, M., Penttila, M. 1997. Laccase from the white-rot fungus Trametes versicolor: cDNA cloning of lcc1 and expression in Pichia pastoris. Current Genetics 32(6): 425-430.
Kim, H., Wi, S., Bae, H. 2007. Biobleaching of softwood kraft pulp using recombinant xylanase and cellulase. Journal of the Korean Wood Science and Technology 35(6): 166-174.

Kim, N.R., Yang, J., Kwon, H., An, J., Choi, W., Kim, W. 2013. Mutations of the TATA-binding protein confer enhanced tolerance to hyperosmotic stress in Saccharomyces cerevisiae. Applied Microbiology and Biotechnology 97(18): 8227-8238.

Lee, S.Y., Kim, M., Kim, S., Hong, C., Ryu, S., Choi I. 2016. Transcriptomic analysis of the white rot fungus Polyporus brumalis provides insight into sesquiterpene biosynthesis. Microbiological Research 182(2016): 141-149.

Lee, S.Y., Ryu, S., Choi, I., Kim, M. 2016. Biosynthesis of eudesmane-type sesquiterpenoids by the woodrotting fungus, Polyporus brumalis, on specific medium, including inorganic magnesium source. Journal of the Korean Wood Science and Technology 44(2): 253-263.

Lee, S.Y., An, J., Ryu, S., Kim, M. 2017. De novo whole-genome sequencing of the wood rot fungus Polyporus brumalis, which exhibits potential terpenoid metabolism. Genome Announcements 5(28): e00586-17.

Lee, J., Yang. I., Igarashi, K., Samejima, M., Choi, I. 2005. Expression of a manganese peroxidase gene (mnp5) from white rot fungus Phanerochaete chrysosporium in the Pichia pastoris. Journal of the Korean Wood Science and Technology 33(4): 45-52.

Peralta-Yahya, P., Ouellet, M., Chan, R., Mukhopadhyay, A., Keasling, J.D., Lee, T.S. 2011. Identification and microbial production of a terpene-based advanced biofuel. Nature Communications 2(2011): 483.

Sambrook, J., Russell, D. 2001. Molecular Cloning: A Laboratory Manual, 3rd edition. New York: Cold Spring Harbor Laboratory Press. 
Sandler, A., Gray, R., Perry, M.C., Brahmer, J., Schiller, J.H., Dowlati, A., Lilenbaum, R., Johnson, D.H. 2006. Paclitaxel carboplatin alone or with bevacizumab for non-small-cell lung cancer. New England Journal of Medicine 355(2006): 2542-2550.

Schnee, C., Kollner, T.G., Gershenzon, J., Degenhardt, J. 2002. The maize gene terpene synthase 1 encodes a sesquiterpene synthase catalyzing the formation of (E)- $\beta$-farnesene, (E)-nerolidol, and (E, E)-farnesol after herbivore damage. Plant Physiology 130(4): 2049-2060.
Tholl, D. 2006. Terpene synthases and the regulation, diversity and biological roles of terpene metabolism. Plant Biology 9(3): 297-304.

Vardakou, M., Salmon, M., Faraldos, J.A., O'Maille, P.E. 2014. Comparative analysis and validation of the malachite green assay for the high throughput biochemical characterization of terpene synthases. MethodsX 1(2014): 187-196

Zhao, Y.D., Yi, Z. 2006. Molecular cloning and expression of yak (Bos grunniens) lactoferrin cDNA in Pichia pastoris. Biotechnology Letters 28(16): 1285-1292. 